\title{
Melt stabilization of polyethylene with natural antioxidants: comparison of a natural extract and its main component
}

\author{
Balázs Kirschweng ${ }^{1,2} \cdot$ Benedek Vörös $^{1,2} \cdot$ Mohammed Arroussi $^{1,2} \cdot$ Dóra Tátraaljai $^{1,2} \cdot$ Miklós Zsuga $^{3}$. \\ Béla Pukánszky ${ }^{1,2}$ (i)
}

Received: 31 August 2019 / Accepted: 15 April 2020 / Published online: 29 April 2020

(c) The Author(s) 2020

\begin{abstract}
The efficiency of the natural extract, silymarin, was compared to its main component, silybin in the processing stabilization of polyethylene. The two compounds were applied as primary antioxidants in the concentration range of 0-500 ppm in combination with 1000 ppm Sandostab PEPQ phosphorous secondary stabilizer. The efficiency of the stabilizers was determined by the measurement of the concentration of unsaturated groups, the amount of residual PEPQ, melt flow rate (MFR), oxidation induction time and color of polymer samples taken after consecutive extrusion steps. The comparison showed that at large concentrations, the extract is more efficient than the pure compound; the vinyl group content and MFR of the polymer are preserved more in the presence on the extract than with silybin. The residual stability of the polymer containing silymarin is also slightly better at the same additive content than that prepared with silybin. Larger efficiency is explained by the smaller bond dissociation enthalpies of the most active phenolic hydroxyl groups of some of the components of the extract. The larger solubility of silymarin resulting from its amorphous character and the presence of the accompanying components of the extract also contributes to its better efficiency. At small concentrations, silymarin proved to be inferior to silybin, which was explained by the interaction of the components. The use of the extract seems to be more advantageous because it is more efficient and significantly cheaper than its pure main component. On the other hand, the stabilizing efficiency of silymarin and the related compounds is inferior to other flavonoids like quercetin, dihydromyricetin or rutin.
\end{abstract}

Keywords Processing stabilization $\cdot$ Long chain branching $\cdot$ Residual stability $\cdot$ Bond dissociation enthalpy $\cdot$ Self-stability $\cdot$ Silymarin · Silybin

\section{Introduction}

Most polymers must be protected against degradation during their processing and very often during their use as well. Polyolefins, including polyethylene (PE) undergoes thermooxidative degradation caused by radical chain reactions.

Béla Pukánszky

bpukanszky@mail.bme.hu

1 Laboratory of Plastics and Rubber Technology, Department of Physical Chemistry and Materials Science, Budapest University of Technology and Economics, P.O. Box 91, Budapest 1521, Hungary

2 Institute of Materials and Environmental Chemistry, Research Centre for Natural Sciences, Hungarian Academy of Sciences, P.O. Box 286, Budapest 1519, Hungary

3 Department of Applied Chemistry, University of Debrecen, P.O. Box 400, Debrecen 4002, Hungary
Polyethylene is stabilized routinely by the combination of a phenolic antioxidant and a secondary stabilizer, usually a phosphite or phosphonite. Light stabilizers might be also added to the additive package, in case the application requires it. The current stabilization practice is well-established, thus very few new stabilizers appeared on the market recently, and no new concept at all. However, some years ago, concerns were raised about the possible environmental and health hazard of phenolic antioxidants and most of the related questions have not been answered yet [1]. Natural antioxidants are already extensively used in the food industry, and they might offer a new way of stabilization also for polymers.

Plants produce and use a large number of antioxidants very efficiently. These can have diverse structures, functions and efficiency. Quite a few of them have been tried as stabilizers also in polymers with different successes. Natural oils [2], carotene [3-6], curcumin [7, 8], vitamin 
E [9-13], lignin [14-18] and many other compounds were shown to have smaller or larger stabilizing activity in a range of polymers, but mostly in polyolefins. Recently, the interest in natural antioxidants has increased considerably and a number of papers have been published on them [2]. Most of these works indicated that at least in polyethylene, flavonoids are the most efficient natural stabilizers. Only a few of the approximately 6000 members of the flavonoid family have been tested as stabilizer up to now, but they proved to be very efficient in PE indeed. Quercetin, dihydromyricetin and rutin provided sufficient melt stability for PE already at $50-100 \mathrm{ppm}$ and residual oxidative stability at $250 \mathrm{ppm}$ [19-21]. All three are considerably more efficient than the phenolic antioxidant used in the largest quantity in current industrial practice. Although natural antioxidants are very efficient, they have several drawbacks as well, their melting temperature can be very high, higher than the processing temperature of PE, their solubility is small and they discolor the polymer.

Silymarin is another member of the flavonoid family. It is a natural extract with a standard composition, and it is widely used in human therapy, mainly for the treatment of ailments related to alcoholism. Silymarin protects and regenerates the liver through its antioxidant and anti-inflammatory effect, but its use has other beneficial consequences as well $[22,23]$. Its main component is silybin, which is used also for the treatment of cancer $[24,25]$. In an earlier study, we investigated the stabilizing effect of silymarin in comparison with quercetin [26]. Application of a natural mixture for stabilization is well-grounded, as many synthetic and natural compounds are used as mixtures in industrial practice because of increased efficiency or smaller price. Sandostab PEPQ, a very efficient secondary stabilizer, contains three compounds. Many other examples can be found from fatty acids, through natural waxes and oils, to many other products [27].

However, poor performance of silymarin [26] raised some questions for us about the benefits of using the pure compound instead of the extract. Accordingly, the goal of this work was to compare the pure compound silybin to the natural extract. We used the same techniques as before [26] and determined the effect of the two products on the degradation and stabilization of PE. We were interested mainly in their efficiency, but also wanted to explain differences, if there were any.

\section{Experimental}

\section{Materials}

The polymer used in the experiments was the Tipelin FS 471 grade ethylene/1-hexene copolymer (melt flow rate: $0.3 \mathrm{~g}$
$10 \mathrm{~min}^{-1}$ at $190{ }^{\circ} \mathrm{C}, 2.16 \mathrm{~kg}$; nominal density: $0.947 \mathrm{~g} \mathrm{~cm}^{-3}$ ) polymerized with a Phillips catalyst. The additive free polymer powder was provided by the MOL Group Ltd., Hungary. Silybin was purchased from Sigma-Aldrich with $95 \%$ purity. Silymarin was the courtesy of the Department of Applied Chemistry at the University of Debrecen [28]. Purple Silybum marianum seeds were collected in the region of Arad, Romania, to produce it. $1200 \mathrm{~g}$ of dried fruits were powdered, homogenized and defatted by hexane in a Soxhlet extractor for $6 \mathrm{~h}$. The resulting powder was dried and then macerated with acetonitrile, the solid was removed by sieving, then the solvent was evaporated and the crude silymarin was washed with ice-cold dichloromethane. The yield was $40 \mathrm{~g}$, which is 3.3 mass\% of the initial quantity. The antioxidants were added to the polymer in various amounts, in $5,10,25,50,100,250$ and $500 \mathrm{ppm}$, to study the effect of additive content on stability. Each compound contained also 1000 ppm Sandostab PEPQ (PEPQ, Clariant) phosphonite secondary stabilizer.

\section{Sample preparation}

The polymer and the additives were mixed with the PE powder and homogenized in a high-speed mixer (Henschel FM/ A10) at the rate of $500 \mathrm{~min}^{-1}$ for $10 \mathrm{~min}$. The dry blend was processed and pelletized in six consecutive extrusion steps at $50 \mathrm{~min}^{-1}$ and barrel temperatures of 180, 220, 260 and $260^{\circ} \mathrm{C}$ under normal laboratory conditions using a Rheomex $\mathrm{S} 3 / 4^{\prime}$ type single screw extruder attached to a Haake Rheocord EU $10 \mathrm{~V}$ driving unit. Samples were taken after each extrusion step. For further studies, films of about 100- $\mu \mathrm{m}$ thickness were compression molded at $190{ }^{\circ} \mathrm{C}$ and $5 \mathrm{~min}$ using a Fontijne SRA 100 machine. Blends of the stabilizers, i.e., the natural antioxidants and PEPQ, were prepared by mixing the components in various amounts to study their interactions.

\section{Characterization}

The melt flow rate (MFR) of the polymer was determined according to the ASTM D $1238-79$ standard at $190^{\circ} \mathrm{C}$ with $2.16 \mathrm{~kg}$ load using a Göttfert MPS-D MFR tester. Residual thermo-oxidative stability was characterized by the oxidation induction time (OIT) measured at $200{ }^{\circ} \mathrm{C}$ in oxygen atmosphere with constant, $20 \mathrm{~cm}^{3} \mathrm{~min}^{-1}$ flow rate in open aluminum pans using a PerkinElmer DSC-7 apparatus. The concentration of the unsaturated functional groups of polyethylene was determined by FTIR spectroscopy on the $100-\mu \mathrm{m}$-thick compression molded films in transmission mode using a Tensor 27 (Bruker) spectrophotometer. Five parallel measurements were carried out on each sample between 4000 and $400 \mathrm{~cm}^{-1}$ wavelengths at $2 \mathrm{~cm}^{-1}$ resolution by 16 scans. The concentration of vinyl groups was 
calculated from the intensity of the absorption peak appearing at $908 \mathrm{~cm}^{-1}$. FTIR spectroscopy was used also for the determination of residual PEPQ content using the absorption of the $\mathrm{P}(\mathrm{III})-\mathrm{O}-\mathrm{C}$ group at $850 \mathrm{~cm}^{-1}$. The color of the samples was characterized by the yellowness index (YI) and the optical L* parameter determined by using a Hunterlab Colourquest $45 / 0$ apparatus. The thermal behavior of silymarin as well as that of its blends with PEPQ and component interactions was studied using a PerkinElmer Diamond DSC-IC apparatus. Differential scanning calorimetric (DSC) measurements were carried out in nitrogen atmosphere with constant, $20 \mathrm{~cm}^{3} \mathrm{~min}^{-1}$ flow rate in open aluminum pans, at a heating rate of $10{ }^{\circ} \mathrm{C} \mathrm{min}^{-1}$ from 0 to $300{ }^{\circ} \mathrm{C}$. The thermal stability of the two natural antioxidants was checked by thermogravimetry using a PerkinElmer STA-6000 apparatus. Samples were heated up to $30-260{ }^{\circ} \mathrm{C}$ at $20{ }^{\circ} \mathrm{C} \mathrm{min}^{-1}$ rate and then held there for $15 \mathrm{~min}$. The measurements were carried out in oxygen atmosphere.

\section{Results and discussion}

The results are discussed in several sections. The composition, structure and characteristics of the two products are compared in the first and then their effect on the properties of the polymer is presented next. Differences in efficiency and their possible reasons are discussed in the last section of the paper, in which relevance for practice is also mentioned briefly.

\section{Composition, properties}

As mentioned above, silymarin is an extract with a standard composition. It is extracted from milk thistle, and it contains $70-80 \%$ flavonolignans and $20-30 \%$ fatty acids. The active component also contains several compounds, three main components and several minor ones, the latter being present in very small amounts. The main component of the active part is silybin; it constitutes about $70 \%$ of the flavonolignans. The composition of the active part and the structure as well as the amount of the components is listed in Table 1. Besides silybin, the other three components are isosilybin, silydianin and silychristin, and their total amount is about $29 \%$ of the active component. The basic structure of the active compounds is similar, but considerable differences can be seen in the moiety attached to the basic flavonoid structure. On the other hand, the number of phenolic $\mathrm{OH}$ groups of the four compounds is very similar, and even their chemical environment does not differ considerably. Accordingly, one would expect similar effect and efficiency in stabilization, i.e., the efficiency of the extract and the pure compound, silybin, should be the same.
The characteristics of the two products are compared to each other in Table 2. As mentioned above, the main features of the chemical structure of the four active components are very similar. Unlike in the case of several of the flavonoids, there is no double bond in ring $\mathrm{C}$. The double bond and the attached $\mathrm{OH}$ group were shown to contribute to stabilization [29]. No phenolic hydroxyl group is located in ring B, and the most active $\mathrm{OH}$ group, which is assumed to take part in stabilization reactions, is located in ring E. As expected, all characteristics of the two products are close, their molecular mass, color and even the number of active phenolic $\mathrm{OH}$ groups are similar. The hydroxyl group located in the D12 position in silydianin was taken into account in the calculation of the number of active phenolic groups of silymarin. Although one would expect the same effect and efficiency from the two products, the extract can be obtained at tenth of the price of the pure compound.

\section{Effect and efficiency}

Degradation during processing usually affects the molecular mass and the viscosity of the polymer. Phillips polyethylenes have one double bond at the end of each chain, and the reaction of this chain-end vinyl group leads to long chain branching and the increase in viscosity [30, 31]. Accordingly, changes in the vinyl group content of the polymer offers information about the efficiency of a stabilizer. The number of vinyl groups per 1000 carbon atoms is plotted against the number of extrusion steps in Fig. 1. Results are presented only for selected compounds to facilitate viewing and to avoid confusion. Silymarin is abbreviated as Sm, while silybin as $\mathrm{Sb}$ in the figure in order to make understanding easier. Vinyl group content decreases quite considerably even at large additive contents indicating that the stabilization efficiency of neither of the products is exceptionally good. Vinyl group content decreases as the result of its reaction with radicals, mostly alkyl centered radicals due to the oxygen poor environment of extrusion. Efficient stabilizers hinder this reaction, and thus vinyl group content does not change or decreases only slightly during multiple extrusions in such cases [32]. Other flavonoid compounds proved to be much more efficient in the stabilization of PE than silymarin and silybin [19-21]. Rather surprisingly, differences can be observed in the efficiency of the two products, which contradicts expectations (see "Composition, properties" section). Vinyl group content decreases drastically at $5 \mathrm{ppm}$ silymarin content, while silybin seems to have a better stabilization efficiency at this composition. At larger concentrations, on the other hand, silymarin seems to be more efficient. A plausible explanation cannot be given for the phenomenon at the moment. A similar effect was observed in the case of rutin [21], which was explained with the thermal degradation of the compound and with component interactions. 
Table 1 Composition and the chemical structure of the components of the natural extract, silymarin [28]

Component

Table 2 Most important characteristics of silymarin, the natural extract and its main component, silybin

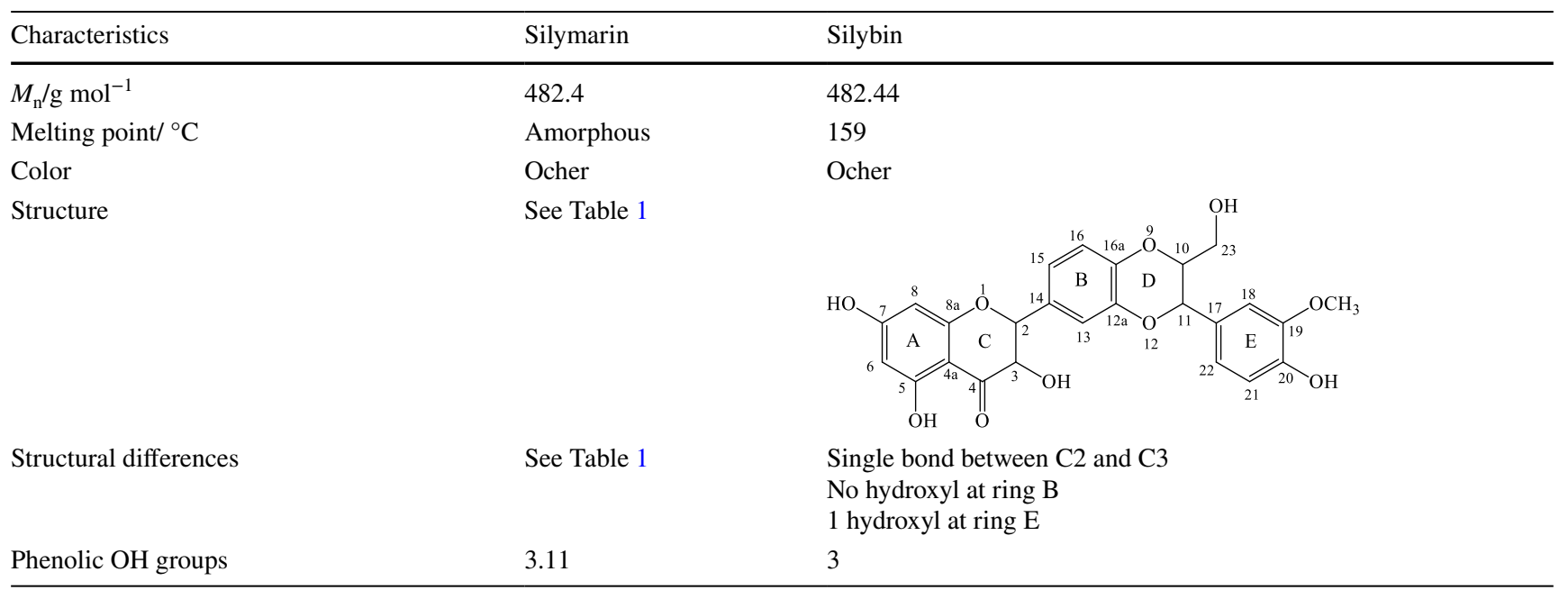




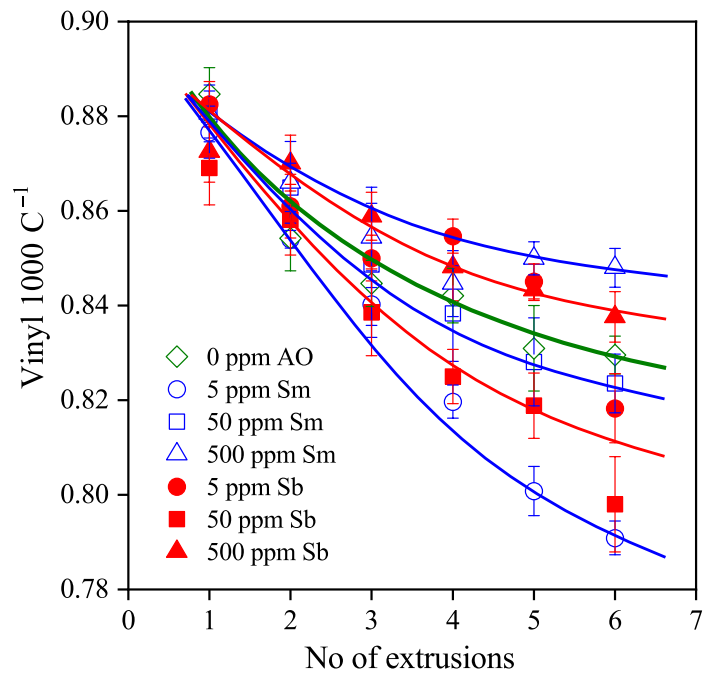

Fig. 1 Effect of additive content and the number of extrusions on the number of vinyl groups in Phillips polyethylene. Symbols: (white diamond) neat, (white circle) $5 \mathrm{ppm} \mathrm{Sm}$, (white square) $50 \mathrm{ppm} \mathrm{Sm}$, (white up-pointing triangle) $500 \mathrm{ppm} \mathrm{Sm}$, (black circle) $5 \mathrm{ppm} \mathrm{Sb}$, (black square) $50 \mathrm{ppm} \mathrm{Sb}$, (black up-pointing triangle) $500 \mathrm{ppm} \mathrm{Sb}$; empty symbols: silymarin, full symbols: silybin

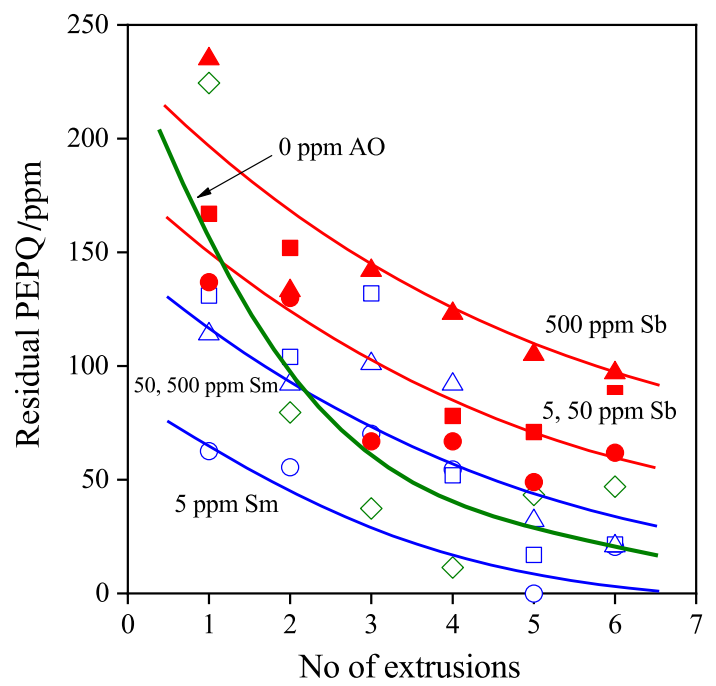

Fig. 2 Residual PEPQ content of the polymer plotted against the number of extrusion steps at various additive contents. Symbols are the same as in Fig. 1

Further data and considerations are needed even for a tentative explanation here.

The residual amount the phosphonite secondary stabilizer is plotted against the number of extrusions in Fig. 2. Phosphorus secondary antioxidants were shown to be essential in processing stabilization $[32,33]$, since they protect the polymer from degradation especially during the first extrusion. The compounds contained 1000 ppm PEPQ before processing, of which very little was preserved in the polymer after

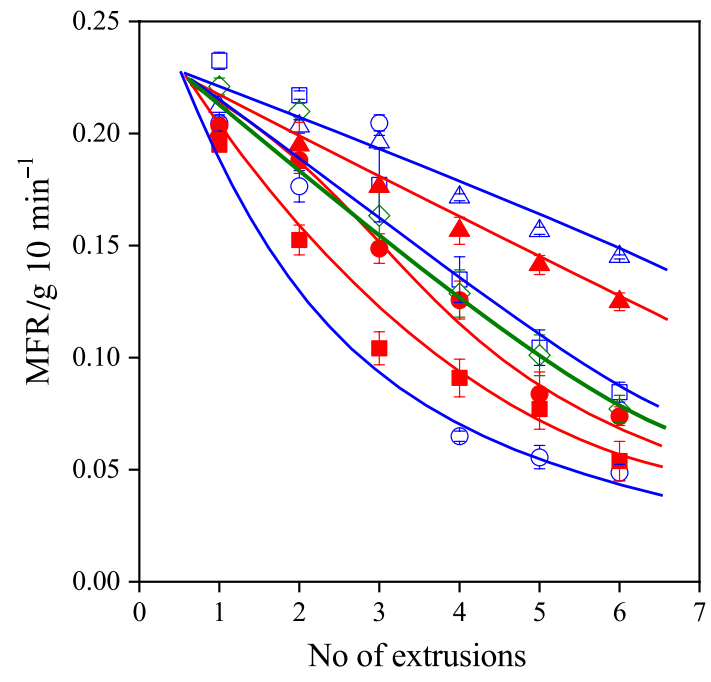

Fig. 3 Dependence of the viscosity (MFR) of the polymer on additive content and processing history. Effect of long chain branching. Symbols are the same as in Fig. 1

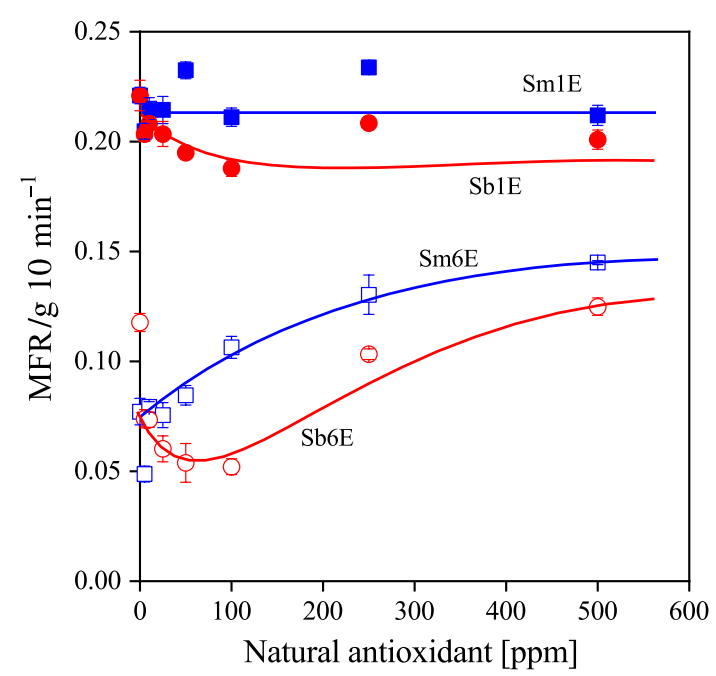

Fig. 4 MFR of polyethylene plotted as a function of the amount of natural antioxidant added to the polymer. Symbols: (white circle, black circle) silybin, (white square, black circle) silymarin; full: first extrusion, empty: sixth extrusion

extrusion. The results presented are even more surprising than those shown in Fig. 1. Silybin is clearly much more efficient in protecting the secondary stabilizer than silymarin; the amount of PEPQ left intact after extrusion is very small in the latter case indeed. Unlike for vinyl group content, silybin is more efficient even at larger concentrations that is a further contradiction needing explanation.

The pivotal point of melt stabilization is maintaining viscosity at the same level during multiple extrusions. The MFR of PE containing various amounts of the two 


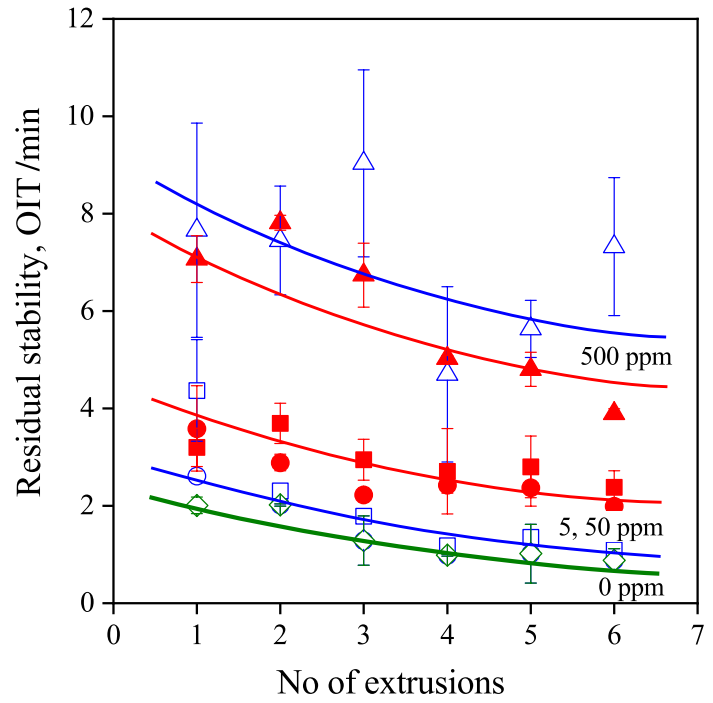

Fig. 5 Effect of the number of extrusions and additive content on the residual stability of PE. Symbols are the same as in Fig. 1

stabilizers is shown in Fig. 3 as a function of processing history. MFR decreases even at larger additive contents showing again the limited efficiency of the flavonoids used in this study for the stabilization of PE. The same differences can be seen in the effect of the two stabilizers, as in the case of the vinyl groups, i.e., silybin is better at small concentrations, while silymarin is more efficient at large additive contents. The similarity calls the attention to the close relationship between vinyl group content and viscosity, on the one hand, and to the effect of some factor or factors resulting in the phenomenon. In Fig. 4, MFR is plotted against the amount of natural antioxidant added to the polymer. The phenomenon mentioned above is clearly shown by the figure. Silymarin is more efficient at large additive contents than silybin after both the first and the sixth extrusion.

The residual stability of the product is an important requirement for many applications including pipes and automotive parts. Residual stability is determined mainly by the amount of the active phenolic antioxidant, but the concentration of the secondary antioxidant and the composition of the additive package also play a role [34]. The dependence of residual stability characterized by the oxygen induction time on the number of processing steps is presented in Fig. 5. Residual stability is very small, less than $10 \mathrm{~min}$, and the standard deviation of the measurement is large. Often at least 20-min residual stability is required in many long-term applications. OIT decreases with increasing number of extrusions as expected. The general tendency can be observed again, silybin is more efficient at small additive contents, while silymarin is better at large concentrations, which proves the consistency

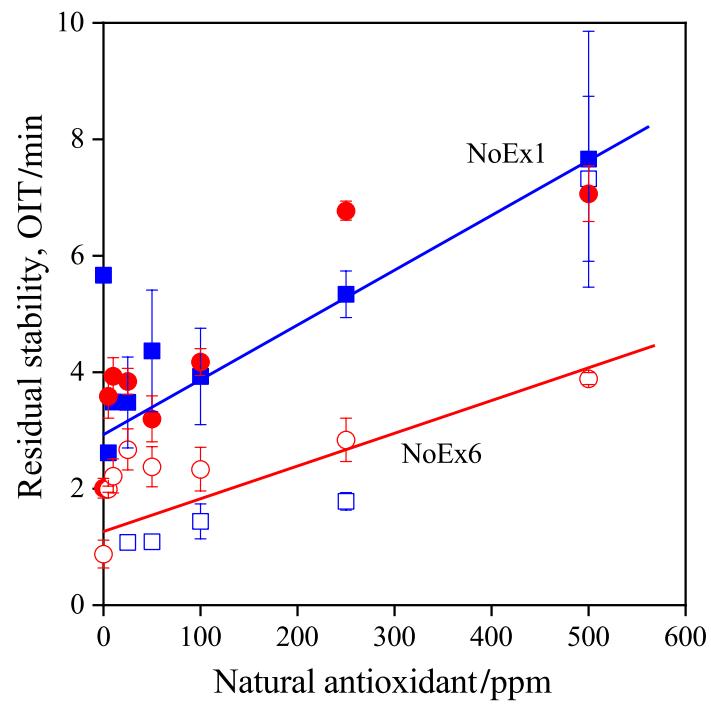

Fig. 6 Influence of the amount of natural antioxidant on the residual stability of polyethylene. Symbols are the same as in Fig. 4

of the measurements and the effect of an unknown factor influencing efficiency. OIT is plotted against additive content in Fig. 6. The scatter of the points is considerable because of the small stability and the large standard deviation of the measurement. Nevertheless, the usual linear correlation is obtained after both the first and the sixth extrusions. The slope of the straight lines differs considerably. Both the small values and the different slope indicate the limited efficiency of these flavonoid-type antioxidants in the stabilization of PE. In the case of very efficient flavonoids, the same slope was obtained for the first and the sixth extrusions that were explained with the large efficiency, as well as the small solubility and continuous resupply of dissolved active stabilizer in subsequent extrusions [19]. Although it is difficult to draw farfetched conclusions about the relative efficiency of the two products, silymarin seems to offer better stability than silybin at concentrations offering some performance.

\section{Discussion}

The consideration of all results presented above in the previous section indicates that contrary to our expectations, at large concentrations, silymarin is a more efficient stabilizer for PE than the pure compound, silybin and some factor or factors decrease the efficiency of silymarin at small additive contents. This phenomenon merits further considerations. The difference of efficiency is difficult to explain, and the interpretation of the results is made even more complicated by the fact that silybin protects the secondary antioxidant better than silymarin at all concentrations. The main role of processing stabilizers is to prevent the reaction of the vinyl 


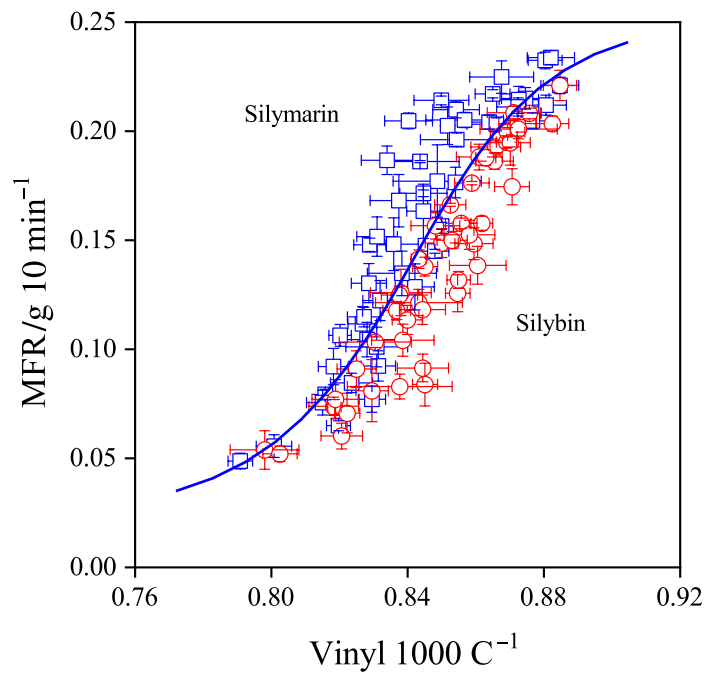

Fig. 7 General correlation between the vinyl group content of polyethylene and its viscosity (MFR). Differences in the efficiency of the two products. Symbols: (white circle) silybin, (white circle) silymarin

Table 3 Bond dissociation enthalpies of the phenolic hydroxyl groups of the main components of silymarin [23]

\begin{tabular}{lllll}
\hline Phenolic $\mathrm{OH}$ at & \multicolumn{4}{c}{ BDE value of OH groups at compound $/ \mathrm{kJ} \mathrm{mol}^{-1}$} \\
\cline { 2 - 5 } & Silybin & Isosilybin & Silydianin & Silychristin \\
\hline A5 & 410.45 & 410.45 & 409.61 & 410.45 \\
A7 & 399.99 & 399.99 & 399.99 & 399.57 \\
C3 & 455.64 & 455.64 & 455.22 & 455.22 \\
B15 & - & - & - & 352.71 \\
D12 & - & - & 412.12 & - \\
E19 & - & - & - & 352.29 \\
E20 & 367.77 & 367.77 & 358.99 & - \\
\hline
\end{tabular}

groups and the formation of long chain branches. The close relationship between vinyl group content and viscosity was shown before [30, 31]. Figure 7 confirms the close correlation again, but also corroborates our conclusion about the larger efficiency of silymarin over silybin. Most of the points obtained on compounds containing silymarin are located above the line drawn to guide the eye, while those for silybin are situated below it.

A tentative explanation for the larger efficiency of silymarin might be offered by the slight differences in the chemical environment of the phenolic $\mathrm{OH}$ groups of the flavonoids leading to different bond dissociation enthalpies (BDE). These enthalpies are listed in Table 3 for all the studied compounds. Phenolic hydroxyl groups located at the positions E19 and E20 have the smallest BDE values, and thus they are supposed to react first with radicals and determine stabilization. Although the E20 hydroxyl group of the main components, silybin and isosilybin, have the same bond

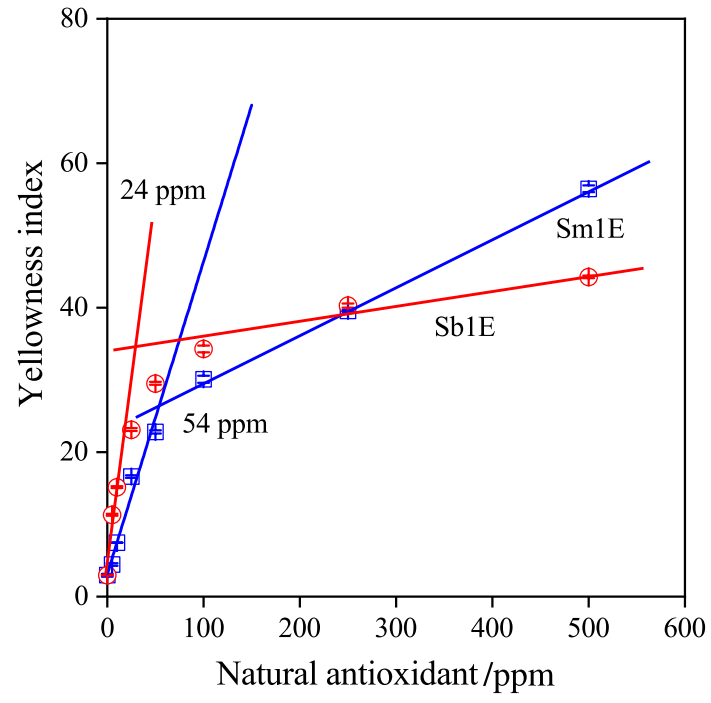

Fig. 8 Determination of the solubility of the natural extract and its main component in polyethylene. First extrusion. Larger solubility of silymarin. Symbols: (white circle) silybin, (white square) silymarin

dissociation enthalpies, silydianin and silychristin have $\mathrm{OH}$ groups with smaller BDE values. The consequence on stabilization is definitely not proportional to composition, the $\mathrm{OH}$ groups with smaller BDE will clearly react first, and thus in spite of their smaller amount, the presence of the two minor components may lead to the larger efficiency of the extract.

Another factor, which merits some consideration, is the solubility of the two products in polyethylene. The solubility of these polar compounds is extremely small in the polymer, and it is very difficult to determine. We estimated solubility earlier from the change in the color of the polymer with increasing additive content [20]. Dissolved flavonoids discolor the polymer very strongly, but above solubility, the additive forms a separate phase, the coloring effect of which is weaker, proportional to the size of the dispersed particles. The color of PE is plotted against its antioxidant content in Fig. 8. The use of the approach described above allows the estimation of solubility, which is larger for silymarin than silybin. Larger solubility means more dissolved molecules and larger probability to scavenge radicals causing degradation. The larger solubility of the active components of silymarin might result from the presence of the accompanying material contained by the extract.

Bond dissociation enthalpies and solubility might explain the larger efficiency of the natural extract, but not its inefficiency at small concentrations. The available results do not offer any ground for a plausible explanation for the phenomenon. Earlier studies showed that the decomposition of the stabilizer itself might decrease its efficiency [21]. This was checked and silymarin had somewhat poorer self-stability than silybin, but the difference was slight. More than one study also indicated that the primary stabilizer, the flavonoid 

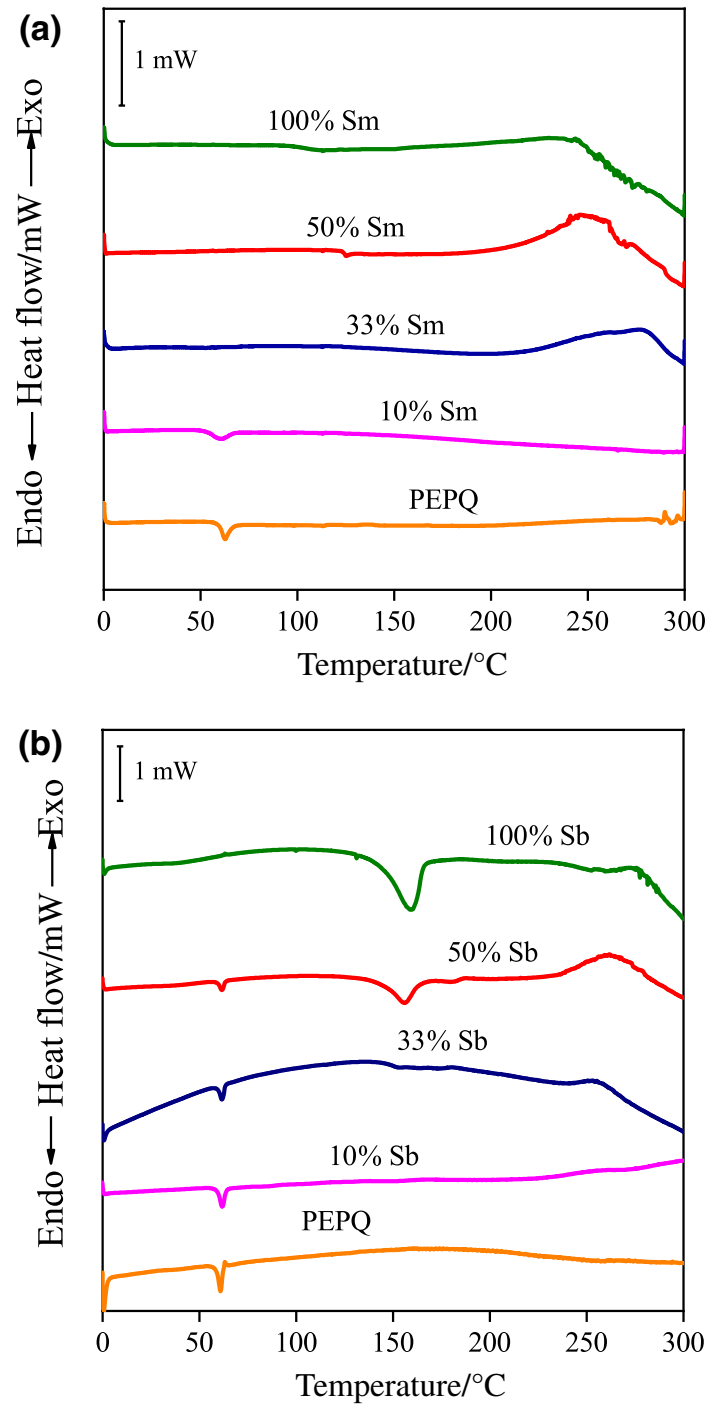

Fig. 9 DSC traces recorded on flavonoid/PEPQ blends with different compositions during heating. Flavonoid content increases from bottom to top. a Silymarin, b silybin

and PEPQ interact with each other [2, 8, 19-21]. This interaction influences efficiency; thus, it is possible that the most active component forms stronger bonds with PEPQ than silybin thus decreasing the efficiency of the extract at small concentrations. Information about the interaction of the two components was obtained earlier from DSC and FTIR measurements [2, 21]. Homogeneous blends were prepared from the two flavonoids and PEPQ. The traces recorded during the heating of the pure components and the blends are presented in Fig. 9a and b. The figures show that silymarin is amorphous, and PEPQ improves its stability, decomposition temperature increases with increase in PEPQ content (Fig. 9a). The degradation of the stabilizer itself was shown to decrease its stabilizing efficiency before [21]. On the other hand, silybin is crystalline, which partly might explain its smaller solubility. Moreover, its combination with PEPQ results in decreased decomposition temperatures (Fig. 9b). The lack of crystallinity for silymarin and the earlier disappearance of the melting peak of PEPQ from the DSC trace in its blends with silymarin than with silybin indicates the formation of stronger interactions in the former case. This interaction may contribute and explain the apparently smaller residual PEPQ content of the blends after extrusion, as well as the larger efficiency of silymarin. Both the role of thermal stability and interactions must be studied more in detail in the future in order to verify the explanation offered here.

\section{Conclusions}

The comparison of the stabilizing efficiency of a natural extract of flavonolignans to its main component showed that the extract is more efficient than the pure compound at large concentrations. The vinyl group content and MFR of the polymer is preserved more in the presence on the extract than with the pure compound, silybin. The residual stability of the polymer containing silymarin is slightly better at the same additive content than that prepared with silybin. Larger efficiency was explained by the smaller bond dissociation enthalpies of the most active phenolic hydroxyl groups of some of the components of the extract. The larger solubility of silymarin probably resulting from its amorphous character and the presence of the accompanying components of the extract may also contribute to its better efficiency. At small concentrations, silymarin proved to be inferior to silybin, which was explained by the interaction of the components. Silybin protected the secondary stabilizer more efficiently than silymarin, but this effect did not manifest itself in better stabilization efficiency. The use of the extract is more advantageous because it is more efficient and significantly cheaper than its pure main component. On the other hand, the stabilizing efficiency of silymarin and the related compounds is inferior to other flavonoids like quercetin, dihydromyricetin or rutin.

Acknowledgements Open access funding provided by Budapest University of Technology and Economics (BME). The National Research, Development, and Innovation Office (NKFIH, Grant No. K 120039) is acknowledged for the financial support of the research.

Open Access This article is licensed under a Creative Commons Attribution 4.0 International License, which permits use, sharing, adaptation, distribution and reproduction in any medium or format, as long as you give appropriate credit to the original author(s) and the source, provide a link to the Creative Commons licence, and indicate if changes were made. The images or other third party material in this article are included in the article's Creative Commons licence, unless indicated otherwise in a credit line to the material. If material is not included in the article's Creative Commons licence and your intended use is not permitted by statutory regulation or exceeds the permitted use, you will 
need to obtain permission directly from the copyright holder. To view a copy of this licence, visit http://creativecommons.org/licenses/by/4.0/.

\section{References}

1. Brocca D, Arvin E, Mosbæk H. Identification of organic compounds migrating from polyethylene pipelines into drinking water. Water Res. 2002;36:3675-80.

2. Kirschweng B, Tátraaljai D, Földes E, Pukánszky B. Natural antioxidants as stabilizers for polymers. Polym Degrad Stab. 2017;145:25-40.

3. Cerruti P, Malinconico M, Rychly J, Matisova-Rychla L, Carfagna $C$. Effect of natural antioxidants on the stability of polypropylene films. Polym Degrad Stab. 2009;94:2095-100.

4. Abdel-Razik EA. Aspects of degradation and stability of ABS copolymers. I. Effect of $\beta$-carotene as antioxidant. J Polym Sci A1. 1989;27:343-55.

5. López-Rubio A, Lagaron JM. Improvement of UV stability and mechanical properties of biopolyesters through the addition of $\beta$-carotene. Polym Degrad Stab. 2010;95:2162-8.

6. Tátraaljai D, Major L, Földes E, Pukánszky B. Study of the effect of natural antioxidants in polyethylene: Performance of $\beta$-carotene. Polym Degrad Stab. 2014;102:33-40.

7. Tátraaljai D, Kirschweng B, Kovács J, Földes E, Pukánszky B. Processing stabilisation of PE with a natural antioxidant, curcumin. Eur Polym J. 2013;49:1196-203.

8. Kirschweng B, Tátraaljai D, Földes E, Pukánszky B. Efficiency of curcumin, a natural antioxidant, in the processing stabilization of PE: concentration effects. Polym Degrad Stab. 2015;118:17-23.

9. Al-Malaika S, Ashley $\mathrm{H}$, Issenhuth $\mathrm{S}$. The antioxidant role of $\alpha$-tocopherol in polymers. I. The nature of transformation products of $\alpha$-tocopherol formed during melt processing of LDPE. J Polym Sci A1. 1994;32:3099-113.

10. Al-Malaika $S$, Goodwin $C$, Issenhuth $S$, Burdick D. The antioxidant role of $\alpha$-tocopherol in polymers II. Melt stabilising effect in polypropylene. Polym Degrad Stab. 1999;64:145-56.

11. Al-Malaika $S$, Issenhuth $S$. The antioxidant role of $\alpha$-tocopherol in polymers III. Nature of transformation products during polyolefins extrusion. Polym Degrad Stab. 1999;65:143-51.

12. Al-Malaika $S$, Issenhuth $S$. The antioxidant role of vitamin $E$ in polymers. IV. Reaction products of DL-a-tocopherol with lead dioxide and with polyolefins. Polymer. 2001;42:2915-39.

13. Al-Malaika $S$, Issenhuth $S$, Burdick $D$. The antioxidant role of vitamin E in polymers V. Separation of stereoisomers and characterisation of other oxidation products of $\mathrm{dl}-\alpha$-tocopherol formed in polyolefins during melt processing. Polym Degrad Stab. 2001;73:491-503.

14. Levon K, Huhtala J, Malm B, Lindberg JJ. Improvement of the thermal stabilization of polyethylene with lignosulphonate. Polymer. 1987;28:745-50.

15. Sadeghifar H, Argyropoulos DS. Correlations of the antioxidant properties of softwood kraft lignin fractions with the thermal stability of its blends with polyethylene. ACS Sustain Chem Eng. 2015;3:349-56.

16. Chodák I, Brezny R, Rychlá L. Blends of polypropylene with lignin. 1. Influence of a lignin addition on cross-linking and thermooxidation stability of polypropylene. Chem Zvesti. 1986;40:461-70.

17. Gregorová A, Cibulková Z, Kosiková B, Simon P. Stabilization effect of lignin in polypropylene and recycled polypropylene. Polym Degrad Stab. 2005;89:553-8.
18. Gregorova A, Košíková B, Staško A. Radical scavenging capacity of lignin and its effect on processing stabilization of virgin and recycled polypropylene. J Appl Polym Sci. 2007;106:1626-31.

19. Tátraaljai D, Földes E, Pukánszky B. Efficient melt stabilization of polyethylene with quercetin, a flavonoid type natural antioxidant. Polym Degrad Stab. 2014;102:41-8.

20. Kirschweng B, Bencze K, Sárközi M, Hégely B, Samu G, Hári J, Tátraaljai D, Földes E, Kállay M, Pukanszky B. Melt stabilization of polyethylene with dihydromyricetin, a natural antioxidant. Polym Degrad Stab. 2016;133:192-200.

21. Kirschweng B, Tilinger DM, Hégely B, Samu G, Tátraaljai D, Földes E, Pukánszky B. Melt stabilization of PE with natural antioxidants: comparison of rutin and quercetin. Eur Polym J. 2018;103:228-37.

22. Fraschini G, Demartini G, Esposti D. Pharmacology of silymarin Clin Drug Investig. 2002;22:51-65.

23. Pyszkova M, Biler M, Biedermann D, Valentová K, Kuzma M, Vrba J, Ulrichová J, Sokolová R, Mojovic M, Popovic-Bijelic A, Kubala M, Trouillas P, Kren V, Vacek J. Flavonolignan 2,3-dehydroderivatives: preparation, antiradical and cytoprotective activity. Free Radic Biol Med. 2016;90:114-25.

24. Gándara L, Sandes E, Venosa GM, Prack MC, Bárbara P, Rodriguez L, Mamone LA, Batlle AMC, Eijan AM, Casas AG. The natural flavonoid silybin improves the response to photodynamic therapy of bladder cancer cells. J Photochem Photobiol B Biol. 2014;133:55-64.

25. Radko L, Cybulski W, Rzeski W. The protective effects of silybin on the cytotoxicity of thiram in human, rat and chicken cell cultures. Pestic Biochem Physiol. 2017;143:154-60.

26. Kirschweng B, Vörös B, Tátraaljai D, Zsuga M, Földes E, Pukánszky B. Natural antioxidants as melt stabilizers for PE: comparison of silymarin and quercetin. Eur Polym J. 2017;90:456-66.

27. Baj T, Baryluk A, Sieniawska E. Application of mixture design for optimum antioxidant activity of mixtures of essential oils from Ocimum basilicum L., Origanum majorana L. and Rosmarinus officinalis L. Ind Crops Prod. 2018;115:52-61.

28. Kuki Á, Nagy L, Deák G, Nagy M, Zsuga M, Kéki S. Identification of silymarin constituents : an improved HPLC-MS method. Chromatographia. 2012;75:175-80.

29. Osorio E, Pérez EG, Areche C, Ruiz LM, Cassels BK, Flórez E, Tiznado W. Why is quercetin a better antioxidant than taxifolin? Theoretical study of mechanisms involving activated forms. J Mol Model. 2013;19:2165-72.

30. Chirinos-Padrón AJ, Hernández PH, Suárez FA. Influences of unsaturation and metal impurities on the oxidative degradation of high density polyethylene. Polym Degrad Stab. 1987;23:935-40.

31. Hoàng EM, Allen NS, Liauw CM, Fontan E, Lafuente P. The thermo-oxidative degradation of metallocene polyethylenes: part 2: thermal oxidation in the melt state. Polym Degrad Stab. 2006;91:1363-72.

32. Kriston I, Orbán-Mester Á, Nagy G, Staniek P, Földes E, Pukánszky B. Melt stabilisation of Phillips type polyethylene, Part I: the role of phenolic and phosphorous antioxidants. Polym Degrad Stab. 2009;94:719-29.

33. Kriston I, Orbán-Mester Á, Nagy G, Staniek P, Földes E, Pukánszky B. Melt stabilisation of Phillips type polyethylene, part II: correlation between additive consumption and polymer properties. Polym Degrad Stab. 2009;94:1448-56.

34. Pospísil J, Horák Z, Pilar J, Billingham NC, Zweifel H, Nespurek $\mathrm{S}$. Influence of testing conditions on the performance and durability of polymer stabilisers in thermal oxidation. Polym Degrad Stab. 2003;82:145-62.

Publisher's Note Springer Nature remains neutral with regard to jurisdictional claims in published maps and institutional affiliations. 